\title{
Arousal Response from Sleep to Tracheal Obstruction in Lambs during Postnatal Maturation
}

\author{
TERESA L. DAVIDSON ${ }^{1}$ AND JAMES E. FEWELL
}

Department of Medical Physiology, University of Calgary, Calgary, Alberta T2N 4N1, Canada

\section{ABSTRACT}

\begin{abstract}
Experiments were carried out to investigate the arousal response from sleep to tracheal obstruction in lambs during postnatal maturation. Ten fetal sheep were instrumented with electrodes for sleep staging and a tracheotomy was done. After spontaneous vaginal delivery, serial experiments were carried out on the lambs at five postnatal ages: $18-48 \mathrm{~h}$ and $4,6,11$, and $18 \mathrm{~d}$. During an experiment, a $5 \mathrm{~F}$ balloon-tipped catheter was inserted into the tracheostomy tube so that tracheal obstruction could be produced by inflating the balloon. Measurements were made in quiet sleep and active sleep during control periods of tidal respiration and during experimental periods of tracheal obstruction. Neither sleep state nor age influenced control arterial $\mathrm{Hb}$ oxygen saturation $\left(\mathrm{SaO}_{2}\right) . \mathrm{SaO}_{2}$ decreased significantly before arousal during tracheal obstruction in quiet sleep at $18-48 \mathrm{~h}$ and in active sleep at all ages. The
\end{abstract}

Arousal from sleep is an important protective mechanism that may guard against severe hypoxemia and death during an apneic episode (1). This may be evident during obstructive apnea, because restoration of upper airway patency and resumption of tidal ventilation are thought to be preceded by arousal from sleep (2-5). In sleeping infants, arousal is associated with complete reopening of the airway when obstructive apnea is produced by neck flexion; in the absence of arousal, reopening of the airway is incomplete or absent (6).

Obstructive apnea during sleep precipitates a cascade of events including hypoxemia, hypercapnia, hypertension, bradycardia, and increased ventilatory effort. A number of these events-hypoxemia (7), hypercapnia (8),

Received April 12, 1993; accepted March 27, 1994

Correspondence and reprint requests: James E. Fewell, Ph.D., Heritage Medical Research Building, University of Calgary, 3330 Hospital Drive, NW, Calgary, Alberta T2N 4N1, Canada.

Supported by the Medical Research Council of Canada (MT-10573). T.L.D. was supported by postdoctoral research fellowships from the Molly Towell Foundation for Perinatal Research and The Canadian Foundation for the Study of Infant Deaths. This work was done during J.E.F.'s tenure as a Medical Scholar of the Alberta Heritage Foundation for Medical Research and a Scientist of the Medical Research Council of Canada.

'Current address: Department of Pediatrics, Rush Medical College, 1653 West Congress Parkway, Chicago, IL 60612.
$\mathrm{SaO}_{2}$ at arousal was always lower in active sleep than in quiet sleep. Overall, however, there were no significant effects of age on the change in $\mathrm{SaO}_{2}$ before arousal in either quiet sleep or active sleep. The time to arousal during tracheal obstruction increased between $18-48 \mathrm{~h}$ and $6 \mathrm{~d}$ of postnatal life in active sleep but not in quiet sleep. Our data provide evidence that the arousal response to tracheal obstruction is functional by $18 \mathrm{~h}$ of postnatal life in lambs. The increase in time to arousal after tracheal obstruction in active sleep most likely results from state-specific changes in the factors governing oxygen supply and demand. (Pediatr Res 36: 501-505, 1994)

\section{Abbreviations \\ $\mathrm{SaO}_{2}$, arterial $\mathrm{Hb}$ oxygen saturation $\mathbf{P a O}_{2}$, arterial partial pressure of oxygen}

and hypertension (9)-are singularly capable of initiating arousal from sleep in young lambs through activation of carotid chemoreceptors, baroreceptors, or both (10-13).

The carotid chemoreceptors-the primary oxygen tension-sensing structures in the arterial circulation (14)reset during early postnatal life in sheep such that the stimulus (arterial oxygen tension)-response (carotid sinus afferent neural activity) curve is shifted to the right (15, 16). The exact time course, however, is presently unknown, and the effect of resetting the carotid chemoreceptors on the postnatal maturation of the arousal response to apnea remains unclear. Accordingly, the purpose of the present study was to investigate the arousal response from sleep to obstructive apnea produced by tracheal obstruction in lambs during postnatal maturation.

\section{METHODS}

Experiments were carried out on 10 chronically instrumented lambs at five postnatal ages. Each lamb was separated from its ewe $1 \mathrm{~d}$ after birth and was housed in a Plexiglas cage in a sound-attenuated environmental chamber (12 light: $12 \mathrm{~h}$ dark, $0700 \mathrm{~h}$ lights on, $25^{\circ} \mathrm{C}, 40 \%$ relative humidity). The lambs had continuous access to 
milk (Lamb Milk Replacer, Land O' Lakes, Inc., Fort Dodge, IA) via an artificial feeding system (Lam-bar, Dalton Supplies Ltd., Henley-On-Thames, Oxon, UK). Experiments were performed with the lambs in the chamber and the recording equipment in an adjacent room.

Surgical preparation. Each lamb underwent two operations before study, one during fetal life between 130 and $140 \mathrm{~d}$ of gestation and one within $12 \mathrm{~h}$ of birth. For the fetal operation, the ewes were anesthetized by inhalation of 4-5\% halothane. Each ewe was then placed supine and its trachea was intubated with a cuffed endotracheal tube; anesthesia was maintained by ventilating the ewe's lungs with halothane $(1.0-1.5 \%)$ in oxygen. The maternal abdomen was shorn and disinfected, and the uterus was exposed through a midline incision below the umbilicus. An incision was made in the uterus and membranes to allow access to the fetus; subsequently, the fetal head and neck were exteriorized. Electrodes for recordings of the electrocorticogram, electrooculogram, and nuchal electromyogram were implanted as previously described for newborn lambs (7). A fetal tracheotomy was also done, and a short length of endotracheal tube was secured in the fetal trachea to maintain patency of the airway. After intrauterine administration of antibiotics (10 million IU of penicillin G sodium and $40 \mathrm{mg}$ of gentamicin sulfate BP), the fetal head and neck were returned to the uterus and the incisions were closed. Additional antibiotics (1 million IU of procaine penicillin G) were administered intramuscularly to the ewe for $7 \mathrm{~d}$ postoperatively.

The lambs delivered by spontaneous vaginal delivery near term of gestation. After birth, each lamb was allowed to remain with its ewe for a minimum of 5 to $6 \mathrm{~h}$ to ensure that the newborn received colostrum. In the newborn, within $12 \mathrm{~h}$ of birth, a double-lumen fiberoptic oximeter catheter (model U440 Opticath, Oximetrix, Inc., Mountain View, CA) was inserted into a femoral artery and advanced to the level of the thoracic aorta for continuous measurement of $\mathrm{SaO}_{2}$ and systemic arterial blood pressure. The arterial catheter remained in place for the duration of the study and was flushed daily with heparinized saline $(10 \mathrm{U} / \mathrm{mL})$ to maintain patency. In addition, the short length of endotracheal tube, previously secured in the trachea, was removed and replaced with a modified fenestrated tracheostomy tube as previously described (17). The modified fenestrated tracheostomy tube allowed the lamb to breathe through an intact upper airway between and during experiments. The lamb was then allowed to recover in a Shor-Line intensive care unit for small animals (Schroer Manufacturing Company, Kansas City, MO) and subsequently returned to its ewe for the night. The next morning, the lamb was separated from its ewe and housed in a Plexiglas cage placed in an environmental chamber. Antibiotics (200 000 IU of procaine penicillin $G$ ) were administered intramuscularly to the lamb for $5 \mathrm{~d}$ after surgery.

Protocol. Obstructions-tracheal and sham-were performed in both quiet sleep and active sleep in serial experiments at $18-48 \mathrm{~h}$ and $4,6,11$, and $18 \mathrm{~d}$ of postnatal life. Tracheal obstructions were accomplished by inflating the balloon of a balloon-tipped catheter (5F SwanGanz, Edwards Laboratory Inc., Anasco, Puerto Rico) that was inserted through the decannulation button into the body of the tracheostomy tube. Sham obstructions were performed in a similar fashion except that the balloon was not inflated; they were interspersed with tracheal obstructions. For each lamb at each postnatal age, we performed six obstructions in quiet sleep (three sham and three tracheal) and six obstructions in active sleep (three sham and three tracheal) during $6 \mathrm{~h}$.

Physiologic measurements were made during 30 -s control periods of tidal respiration and during experimental periods of tracheal obstruction. Because mean period lengths of quiet and active sleep of chronically instrumented lambs during this age range are 6 to $7 \mathrm{~min}$ and 3 to $4 \mathrm{~min}$, respectively (Johnson P, unpublished work), control measurements were made 2 min after the lamb entered quiet sleep and $30 \mathrm{~s}$ after the lamb entered active sleep. All experiments began at $1200 \mathrm{~h}$ to avoid any possible influence of circadian variation on the arousal response.

Determination of sleep state and arousal. Once the animal was lying down, the following electrophysiologic criteria were used to define sleep state (7): During quiet wakefulness, the electrocorticogram exhibited a fast-wave lowvoltage pattern; there were occasional eye movements and there was tonic activity on the nuchal electromyogram. During quiet sleep, the electrocorticogram exhibited a slow-wave high-voltage pattern; there were no eye movements and there was tonic activity on the nuchal electromyogram. During active sleep, the electrocorticogram exhibited a fast-wave low-voltage pattern; there were rapid eye movements; there was no activity on the nuchal electromyogram; and there were occasional ear, facial, and limb twitches. Each lamb was allowed to cycle through at least one period of quiet sleep before the experiment actually began so that we could determine the amplitude of electrocortical activity and set strict criteria for defining quiet sleep.

Arousal was defined as follows: During quiet sleep, the point of arousal was determined by a change in the electrocorticogram from a slow-wave high-voltage pattern to a fast-wave low-voltage pattern with continued activity on the nuchal electromyogram (7). During active sleep, the point of arousal was determined by a return of tonic activity on the nuchal electromyogram with continued fast-wave low-voltage activity on the electrocorticogram.

Measurements. During an experiment, the electrophysiologic signals, $\mathrm{SaO}_{2}$, systemic arterial blood pressure, and respiratory frequency were recorded on a Grass model 7E polygraph (Grass Medical Instruments, Quincy, MA). The three electrophysiologic leads were connected to differential high-impedance probes (model 7H1P5, model 7P5 Wide Band A.C. EEG Pre-amplifier, Grass Medical Instruments) and were high-pass filtered 
using the $1 / 2$-amplitude low-frequency response control on the A.C. preamplifiers (electrocorticogram $0.3 \mathrm{~Hz}$, electrooculogram $1.0 \mathrm{~Hz}$, and electromyogram $10 \mathrm{~Hz}$ ).

For measurement of $\mathrm{SaO}_{2}$, the fiberoptic portion of the catheter was connected to the optical module of the oximeter processor. The femoral catheter was connected to a strain-gauge pressure transducer (Gould P23ID, Gould Inc., Oxnard, CA) using rigid pressure monitoring tubing to measure systemic arterial pressure; the transducer was placed at the approximate level of the heart when the animal was lying down. Heart rate was determined from the pulsatile blood pressure tracing. Respiratory frequency was measured by impedance plethysmography (Respitrace, Non-Invasive Monitoring System, Inc., Ardsley, NY).

Statistical analysis. For each experiment, we determined an average value for each variable during the control period and during the experimental period immediately preceding arousal from quiet sleep or active sleep. Control heart rate and systolic arterial pressure were calculated as the mean of the 10 beats preceding airway obstruction; arousal heart rate and systolic arterial pressure were calculated as the mean of the 10 beats immediately preceding arousal. Control respiratory frequency was calculated as the mean of the five breaths preceding airway obstruction; arousal respiratory frequency was calculated as the mean of the three to five breaths immediately preceding arousal. To analyze the data statistically, we performed a two-factor analysis of variance for repeated measures to determine whether sleep state or postnatal age affected the measured or calculated variables (18). If there was a significant difference, a Duncan's multiple comparison test was performed to determine which means were statistically different (19).

\section{RESULTS}

Neither sleep state nor age influenced control $\mathrm{SaO}_{2}$ (Table 1). $\mathrm{SaO}_{2}$ decreased significantly before arousal during tracheal obstruction in quiet sleep at $18-48 \mathrm{~h}$ and in active sleep at all ages. The $\mathrm{SaO}_{2}$ at arousal was always lower in active sleep than in quiet sleep. Overall, however, there were no significant effects of age on the change in $\mathrm{SaO}_{2}$ before arousal in either quiet sleep or active sleep. The time to arousal during tracheal obstruction increased between $18-48 \mathrm{~h}$ and $6 \mathrm{~d}$ of postnatal life in

Table 1. Control and arousal $\mathrm{SaO}_{2}(\%)$ for tracheal obstructions in 10 lambs*

\begin{tabular}{|c|c|c|c|c|}
\hline \multirow{2}{*}{$\begin{array}{l}\text { Postnatal } \\
\text { age }\end{array}$} & \multicolumn{2}{|c|}{ Quiet sleep } & \multicolumn{2}{|c|}{ Active sleep } \\
\hline & Control & Arousal & Control & Arousal \\
\hline $18-48 \mathrm{~h}$ & $91 \pm 3$ & $83 \pm 9 \dagger$ & $88 \pm 6$ & $76 \pm 12 \dagger$ \\
\hline $4 d$ & $91 \pm 4$ & $84 \pm 10$ & $90 \pm 5$ & $76 \pm 13 t$ \\
\hline $6 \mathrm{~d}$ & $89 \pm 4$ & $82 \pm 10$ & $88 \pm 6$ & $75 \pm 13 \dagger$ \\
\hline $11 \mathrm{~d}$ & $90 \pm 3$ & $87 \pm 4$ & $89 \pm 3$ & $79 \pm 8 \dagger$ \\
\hline $18 \mathrm{~d}$ & $88 \pm 5$ & $84 \pm 9$ & $86 \pm 6$ & $74 \pm 13+$ \\
\hline
\end{tabular}

* Values are means $\pm 1 \mathrm{SD}$.

$+p<0.05$ for control $v s$ arousal. active sleep but not in quiet sleep (Fig. 1). The average time to arousal during sham obstruction exceeded $75 \mathrm{~s}$ in quiet sleep and active sleep.

Systolic arterial blood pressure increased during postnatal maturation and tended to increase during tracheal obstruction before arousal in both sleep states (Table 2). Control heart rate and respiratory frequency decreased significantly by d 18 in both quiet sleep and active sleep (Tables 3 and 4). Control heart rate was decreased during active sleep compared with quiet sleep, but control respiratory frequency was not influenced by sleep state. Heart rate and respiratory frequency decreased during tracheal obstruction; the changes in heart rate were greater during active sleep than during quiet sleep.

\section{DISCUSSION}

Our experiments provide new and important information about the arousal response from sleep to tracheal obstruction in lambs during postnatal maturation. Neither sleep state nor age influenced control $\mathrm{SaO}_{2} \cdot \mathrm{SaO}_{2}$ decreased significantly before arousal during tracheal obstruction at $18-48 \mathrm{~h}$ in quiet sleep and at all ages in active sleep. Overall, however, there were no significant effects of age on the change in $\mathrm{SaO}_{2}$ before arousal in either quiet sleep or active sleep.

Thus, it appears from our data that during postnatal maturation there is little variation in the change in $\mathrm{SaO}_{2}$ before arousal in response to tracheal obstruction. However, if one considers the shift in the oxyhemoglobin dissociation curve that occurs during the first $3 \mathrm{wk}$ of postnatal life in lambs (20), control and arousal $\mathrm{PaO}_{2}$ would be approximately 10 torr higher on d 18 compared with that measured at $18-48 \mathrm{~h}$ of postnatal life. Thus, although the $\mathrm{PaO}_{2}$ at arousal during tracheal obstruction increased, the change in $\mathrm{PaO}_{2}$ from control before arousal most likely remained the same. It is not yet known, however, whether the carotid chemoreceptors initiate arousal during tracheal obstruction at a given oxygen

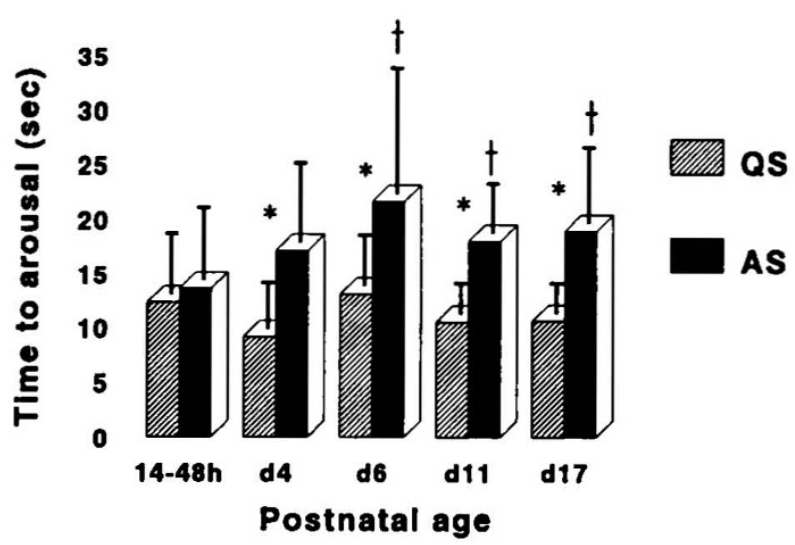

Figure 1. Effect of postnatal age and sleep state on time to arousal after tracheal obstruction. Data are presented as means $\pm 1 \mathrm{SD}$ for $n=10$ lambs at postnatal ages $18-48 \mathrm{~h}$ and 4,6 , and $11 \mathrm{~d}$ and $n=9$ lambs at $18 \mathrm{~d} .{ }^{*}, p<0.05$ for quiet sleep $(Q S) v s$ active sleep $(A S)$ at a given postnatal age; †, $p<0.05$ for age $v s 18-48 \mathrm{~h}$ in a given sleep state. 
Table 2. Control and arousal systolic arterial blood pressure $(\mathrm{mm} \mathrm{Hg})$ during tracheal obstructions in 10 lambs*

\begin{tabular}{llcllc}
\hline \multirow{2}{*}{$\begin{array}{c}\text { Postnatal } \\
\text { age }\end{array}$} & \multicolumn{2}{c}{ Quiet sleep } & & \multicolumn{2}{c}{ Active sleep } \\
\cline { 2 - 3 } \cline { 5 - 6 } \cline { 5 - 6 } Control & Arousal & & Control & Arousal \\
\hline $18-48 \mathrm{~h}$ & $84 \pm 8$ & $91 \pm 8 \dagger$ & & $83 \pm 7$ & $91 \pm 8$ \\
$4 \mathrm{~d}$ & $91 \pm 5$ & $95 \pm 7$ & & $90 \pm 6$ & $98 \pm 9$ \\
$6 \mathrm{~d}$ & $85 \pm 5$ & $99 \pm 12 \dagger$ & & $86 \pm 9$ & $92 \pm 7$ \\
$11 \mathrm{~d}$ & $97 \pm 3 \ddagger$ & $106 \pm 6 \ddagger$ & & $99 \pm 4 \ddagger$ & $104 \pm 10 \ddagger$ \\
$18 \mathrm{~d}$ & $94 \pm 5$ & $98 \pm 8$ & & $93 \pm 5$ & $98 \pm 7$ \\
\hline
\end{tabular}

* Values are means \pm 1 SD.

$\dagger p<0.05$ for control $v s$ arousal.

$\ddagger p<0.05$ vs $18-48 \mathrm{~h}$ in a given sleep state and experimental period.

tension threshold, which would most likely change with chemoreceptor resetting during early postnatal life, or whether arousal is initiated by the carotid chemoreceptors once a given change in the oxygen tension has occurred, which would probably not change with chemoreceptor resetting during early postnatal life. Because our experiments were not designed to answer this question, additional studies are necessary.

We were surprised to find that the time to arousal during tracheal obstruction increased in the first week of life in active sleep but not in quiet sleep. Because the time to arousal increased in active sleep during postnatal maturation yet control and arousal $\mathrm{SaO}_{2}$ remained constant, there must have been a decrease in the rate of arterial $\mathrm{Hb}$ oxygen desaturation during tracheal obstruction. The times to arousal from both quiet sleep and active sleep for lambs $6 \mathrm{~d}$ of age and older are comparable to those previously reported from our laboratory $(17,21)$. There are a number of possible physiologic mechanisms that might influence the rate of arterial $\mathrm{Hb}$ oxygen desaturation during tracheal obstruction in an age- and statespecific fashion. The primary factors that determine the rate of arterial $\mathrm{Hb}$ oxygen desaturation during apnea are the body oxygen stores and the metabolic consumption of oxygen $(22,23)$. Qualitatively, the most important body oxygen store is in the lungs and is governed by lung volume (i.e. the functional residual capacity if apnea occurs at end-expiration).

From the standpoint of body oxygen stores, one might speculate that the decrease in functional residual capacity during active sleep compared with that in quiet sleep, which is thought to result primarily from the loss of

Table 3. Control and arousal heart rate (beats/min) during tracheal obstructions in 10 lambs*

\begin{tabular}{lccccc}
\hline \multirow{2}{*}{$\begin{array}{c}\text { Postnatal } \\
\text { age }\end{array}$} & \multicolumn{2}{c}{ Quiet sleep } & & \multicolumn{2}{c}{ Active sleep } \\
\cline { 2 - 3 } \cline { 5 - 6 } \cline { 5 - 6 } & Control & Arousal & & Control & Arousal \\
\hline $18-48 \mathrm{~h}$ & $191 \pm 32$ & $168 \pm 31 \dagger$ & & $164 \pm 27 \ddagger$ & $143 \pm 30 \dagger$ \\
$4 \mathrm{~d}$ & $181 \pm 20$ & $160 \pm 31 \dagger$ & & $161 \pm 19 \ddagger$ & $117 \pm 34 \dagger$ \\
$6 \mathrm{~d}$ & $185 \pm 20$ & $148 \pm 36 \dagger$ & & $172 \pm 21$ & $122 \pm 38 \dagger$ \\
$11 \mathrm{~d}$ & $188 \pm 23$ & $154 \pm 27 \dagger$ & & $162 \pm 23 \ddagger$ & $106 \pm 34 \dagger$ \\
$18 \mathrm{~d}$ & $154 \pm 20 \S$ & $132 \pm 23 \dagger$ & & $134 \pm 16 \ddagger \S$ & $117 \pm 27 \dagger$ \\
\hline
\end{tabular}

* Values are means $\pm 1 \mathrm{SD}$.

$\dagger p<0.05$ for control $v s$ arousal.

$\ddagger p<0.05$ for quiet sleep control $v s$ active sleep control.

$\S p<0.05 v s 18-48 \mathrm{~h}$ in a given sleep state and experimental period.
Table 4. Control and arousal respiratory frequency (breaths/min) during tracheal obstructions in 10 lambs*

\begin{tabular}{llllll}
\hline \multirow{2}{*}{$\begin{array}{c}\text { Postnatal } \\
\text { age }\end{array}$} & \multicolumn{2}{c}{ Quiet sleep } & & \multicolumn{2}{c}{ Active sleep } \\
\cline { 2 - 3 } \cline { 5 - 6 } & Control & Arousal & & Control & Arousal \\
\hline $18-48 \mathrm{~h}$ & $75 \pm 14$ & $70 \pm 22$ & & $71 \pm 14$ & $66 \pm 17$ \\
$4 \mathrm{~d}$ & $62 \pm 10$ & $58 \pm 11$ & & $71 \pm 11$ & $57 \pm 11$ \\
$6 \mathrm{~d}$ & $75 \pm 22$ & $64 \pm 15$ & & $81 \pm 22$ & $61 \pm 15 \dagger$ \\
$11 \mathrm{~d}$ & $70 \pm 29$ & $58 \pm 13 \dagger$ & & $70 \pm 16$ & $55 \pm 14 \dagger$ \\
$17 \mathrm{~d}$ & $49 \pm 8 \ddagger$ & $46 \pm 12$ & & $58 \pm 7 \ddagger$ & $46 \pm 8 \dagger$ \\
\hline
\end{tabular}

* Values are means $\pm 1 \mathrm{SD}$.

$\dagger p<0.05$ for control $v s$ arousal.

$\ddagger p<0.05 v$ s $18-48 \mathrm{~h}$ in a given sleep state and experimental period.

intercostal muscle tone $(24,25)$, would become attenuated during postnatal maturation as the rib cage becomes less compliant. This would serve to decrease the rate of arterial $\mathrm{Hb}$ oxygen desaturation during apnea in active sleep but not quiet sleep.

From the standpoint of metabolic consumption of oxygen, one might speculate that sleep state-specific influences on effector mechanisms used for thermoregulation in the newborn might decrease metabolic consumption of oxygen in active sleep but not quiet sleep during postnatal maturation; this would serve to attenuate the rate of arterial $\mathrm{Hb}$ oxygen desaturation during apnea in active sleep. In the immediate newborn period, nonshivering thermogenesis is the primary source of heat production. Nonshivering thermogenesis is thought to occur in active sleep as well as in quiet sleep and quiet wakefulness (26). In older lambs, however, shivering thermogenesis is the primary source of heat production. Because shivering thermogenesis is inhibited during active sleep (27), metabolic oxygen consumption may be decreased in this sleep state. The switch from nonshivering to shivering thermogenesis occurs early in a precocial species such as the sheep (28).

The arousal response from sleep has been suggested to be an important protective mechanism that may prevent severe hypoxemia and death during an apneic episode (1). Apnea occurs to some extent in almost all preterm (29) and term (30) infants and may thus be considered a normal event in neonatal life. The difference between normal infants and victims of sudden infant death syndrome may lie in the arousal response to apnea during sleep (31). Guntheroth (31) has hypothesized that the crucial area of abnormal physiology in sudden infant death syndrome is arousal after apnea. The importance of the arousal response has been suggested to be at least 2 -fold. First, wakefulness per se is a potent stimulus to breathing. Second, arousal permits the initiation of behavioral and ventilatory responses to the stimulus; arousal is generally thought to precede resumption of tidal ventilation during apnea $(2-4)$.

The results of our studies may have implications for sudden infant death syndrome. If the final event is apnea, as has been hypothesized $(31,32)$, data from our previous studies would allow one to speculate that 1 ) if the rate of oxygen decrease is great enough during apnea in active 
sleep, arousal may fail to occur before electrocortical signs of cerebral hypoxia and primary apnea occur (7);2) if an infant is repeatedly exposed to hypoxemia, the arousal response to apnea might be impaired (33-35); and 3 ) if carotid chemoreceptor or carotid baroreceptor function is impaired, arousal may fail to occur in response to potentially harmful respiratory stimuli such as hypoxemia or hypercapnia during apnea (10-12). Lastly, data from our present experiments provide evidence that, although there are quantitative state-specific changes in the arousal response to tracheal obstruction during postnatal maturation (i.e. the $\mathrm{SaO}_{2}$ at arousal in quiet sleep and the time to arousal in active sleep), qualitatively the arousal response to tracheal obstruction appears to be fully functional soon after birth in healthy lambs. Thus, we would speculate that if abnormalities in the arousal response do indeed play a role in the pathophysiology of sudden infant death, then the abnormalities are acquired due to either prenatal (e.g. exposure to various drugs) or postnatal (e.g. repetitive exposure to hypoxia) insult rather than to a specific window of vulnerability in normal development of the arousal response to cardiorespiratory stimuli.

Acknowledgment. The authors thank Colleen S. Kondo for technical assistance.

\section{REFERENCES}

1. Phillipson EA, Sullivan CE 1978 Arousal: the forgotten response to respiratory stimuli. Am Rev Respir Dis 118:807-809

2. Gastaut H, Tassinari CA, Duron B 1966 Polygraphic study of episodic diurnal and nocturnal (hypnic and respiratory) manifestations of the Pickwickian syndrome. Brain Res 2:167-186

3. Walsh RE, Michealson ED, Harkerload LE, Zichelboim A, Sackner MA 1972 Upper airway obstruction in obese patients with sleep disturbances and somnolence. Ann Intern Med 76:185-192

4. Remmers JE, deGroot WJ, Sauerland EK, Anch AM 1978 Pathogenesis of upper airway occlusion during sleep. J Appl Physiol 44:931-938

5. Frank Y, Kravath RE, Pollak CP, Weitzman ED 1983 Obstructive sleep apnea and its therapy: clinical and polysomnographic manifestations. Pediatrics 71:737-740

6. Stark AR, Thach BT 1981 Recovery of airway patency after obstruction in normal infants. Am Rev Respir Dis 123:691-693

7. Fewell JE, Baker SB 1987 Arousal from sleep during rapidly developing hypoxemia in lambs. Pediatr Res 22:471-477

8. Fewell JE, Baker SB 1989 Arousal and cardiopulmonary response to hyperoxic hypercapnia in lambs. J Dev Physiol 12:21-26

9. Fewell JE, Johnson P 1984 Acute increases in blood pressure cause arousal from sleep in lambs. Brain Res 311:259-265

10. Fewell JE, Kondo CS, Dascalu V, Filyk SC 1989 Influence of carotid denervation on the arousal and cardiopulmonary response to rapidly developing hypoxemia in lambs. Pediatr Res 25:473-477

11. Fewell JE, Kondo CS, Dascalu V, Filyk SC 1989 Influence of carotid denervation on the arousal and cardiopulmonary responses to alveolar hypercapnia in lambs. J Dev Physiol 12:193-199
12. Fewell JE, Taylor BJ, Kondo CS, Dascalu V, Filyk SC 1990 Influence of carotid denervation on the arousal and cardiopulmonary responses to upper airway obstruction in lambs. Pediatr Res 28:374-378

13. Horne RS, DePreu ND, Berger PJ, Walker AM 1991 Arousal responses to hypertension in lambs: effect of sinoaortic denervation. Am J Physiol 260:H1283-H1289

14. Fitzgerald RS, Lahiri S 1986 Reflex responses to chemoreceptor stimulation. In: Fishman AP, Cherniack NS, Widdicombe JG, Geiger SR (eds) Handbook of Physiology, Section 3: The Respiratory System. American Physiological Society, Bethesda, MD, pp 313-362

15. Blanco CE, Dawes GS, Hanson MA, McCooke HB 1984 The response to hypoxia of arterial chemoreceptors in fetal sheep and newborn lambs. J Physiol (Lond) 351:25-37

16. Hanson MA, Kumar P, McCooke HB 1986 Postnatal resetting of carotid chemoreceptor sensitivity in the lamb. J Physiol (Lond) 382:57(abstr)

17. Fewell JE 1987 The effect of short-term sleep fragmentation produced by intense auditory stimuli on the arousal response to upper airway obstruction in lambs. J Dev Physiol 9:409-417

18. Winer BJ 1971 Two-factor experiments with repeated measures on one factor. In: Statistical Principles in Experimental Design. McGraw-Hill, New York, pp 518-538

19. Zar JH 1979 Multiple comparisons. In: Biostatistical Analysis. Prentice-Hall, Englewood Cliffs, NJ, pp 151-162

20. Lister G, Walter TK, Versmold HT, Dallman PR, Rudolph AM 1979 Cardiovascular and hematological determinants of oxygen delivery: developmental changes in lambs. Am J Physiol 237:H668-H675

21. Baker SB, Fewell JE 1987 Effects of hyperoxia on the arousal response to upper airway obstruction in lambs. Pediatr Res 21:116-120

22. Farhi LE 1964 Gas stores in the body. In: Fenn WD, Rahn H (eds) Handbook of Physiology, Volume 1: Respiration. American Physiological Society, Bethesda, MD, pp 873-885

23. Henderson-Smart DJ 1980 Vulnerability to hypoxemia in the newborn. Sleep 3:331-342

24. Henderson-Smart DJ, Read DJC 1979 Reduced lung volume during behavioral active sleep in the newborn. J Appl Physiol 46:1081-1085

25. Henderson-Smart DJ, Read DJC 1978 Depression of intercostal and abdominal muscle activity and vulnerability to asphyxia during active sleep in the newborn. In: Guilleminault C, Dement WC (eds) Sleep Apnea Syndromes. Alan R. Liss, New York, pp 93-117

26. Fewell JE, Kondo CS, Dascalu V 1990 Influence of sleep on the cardiovascular and metabolic responses to a decrease in ambient temperature in lambs. J Dev Physiol 13:223-230

27. Parmeggiani PL 1980 Temperature regulation during sleep: a study in homeostasis. In: Orem J, Barnes CD (eds) Physiology in Sleep. Academic Press, London, pp 97-143

28. Nedergaard J, Connolly E, Cannon B 1994 Brown adipose tissue in the mammalian neonate. In: Trayhurn P, Nicholls DG (eds) Brown Adipose Tissue. Edward Arnold Pty Ltd, London, pp 152-213

29. Read DJC, Henderson-Smart DJ 1984 Regulation of breathing in the newborn during different behavioral states. Annu Rev Physiol 46:675-685

30. Southall DP, Richards J, Brown DJ, Johnston PGB, DeSwiet M, Shinebourne EA 1980 Twenty-four-hour recordings of ECG and respiration in the newborn infant with findings related to sudden death and unexplained brain damage in infancy. Arch Dis Child 55:7-16

31. Guntheroth WG 1983 Arrhythmia, apnea or arousal? In: Tildon WT, Rolder LM, Steinschneider A (eds) Sudden Infant Death Syndrome. Academic Press, London, pp 263-269

32. Steinschneider A 1982 Prolonged apnea and the sudden infant death syndrome: clinical and laboratory observations. Pediatrics 50:646-654

33. Fewell JE, Williams BJ, Szabo JS, Taylor BJ 1988 Influence of repeated upper airway obstruction on the arousal and cardiopulmonary response to upper airway obstruction in lambs. Pediatr Res 23:191-195

34. Fewell JE, Konduri GG 1989 Influence of repeated exposure to rapidly developing hypoxaemia on the arousal and cardiopulmonary response to rapidly developing hypoxaemia in lambs. J Dev Physiol 11:77-82

35. Fewell JE, Konduri GG 1988 Repeated exposure to rapidly developing hypoxemia influences the interaction between oxygen and carbon dioxide in initiating arousal from sleep in lambs. Pediatr Res 24:28-33 